\title{
Artikel
}

\section{Het pleitbaar standpunt als bijzondere strafuitsluitingsgrond?}

Prof. mr. G.J.M.E. (Guido) de Bont*

\section{Inleiding}

Pas in 2017 heeft de strafkamer van de Hoge Raad het zogeheten 'pleitbaar standpunt' uit het fiscale boeterecht een plaats gegeven in de strafrechtelijke doctrine, door aan te geven op welke wijze een dergelijk verweer in het kader van de vragen ingevolge artikel 348/350 Sv dient te worden aangemerkt. Voordien werd dit verweer in de literatuur op verschillende wijzen geduid: als een opzetverweer, als een schulduitsluitingsgrond of als een bijzonder verweer in verband met het (geobjectiveerde) strekkingsvereiste in artikel 69 lid 2 Algemene wet inzake rijksbelastingen (hierna ook: AWR). ${ }^{1}$

De Hoge Raad heeft deze discussie beslecht door het beroep op een pleitbaar standpunt in het strafrecht te plaatsen in de sleutel van het (voorwaardelijk) opzet. Met deze keuze is echter nog niet duidelijk op welke wijze een pleitbaar standpunt in het strafrecht een rol kan vervullen bij culpoze delicten, zoals bijvoorbeeld in artikel 68 AWR.

Hierna wordt allereerst de recente jurisprudentie omtrent het pleitbaar standpunt binnen het leerstuk van opzet in het strafrecht toegelicht. Vervolgens wordt nader ingegaan op de fiscale jurisprudentie van de Hoge Raad omtrent de werking van een pleitbaar standpunt

Guido de Bont is advocaat bij De Bont Advocaten en hoogleraar formeel belastingrecht aan de Erasmus Universiteit Rotterdam.

1. Zie J.W. Ilsink, 'Enkele gedachten over het fiscale pleitbare standpunt in strafzaken', in: L.J.A. Pieterse (red.), Draaicirkels van formeel belastingrecht (vriendenbundel Niessen) SDU: 2009, en bijv. J.P. Cnossen, ‘De afnemende waarde van "het algemene"', Strafblad 2017/6, p. 475. bij delicten, waarbij opzet geen bestanddeel vormt. Eerst wordt de situatie behandeld waarin schuld als bestanddeel in de delictsomschrijving is opgenomen. Vervolgens wordt met betrekking tot de delictsomschrijvingen waarin opzet noch (grove) schuld als bestanddeel is opgenomen, bezien in hoeverre het pleitbaar standpunt kan worden aangemerkt als een erkende strafuitsluitingsgrond dan wel of er argumenten bestaan om een bijzondere strafuitsluitingsgrond aanwezig te achten.

\section{Het pleitbaar standpunt}

In het standaardarrest van 21 april $2017^{2}$ (hierna ook: Credit Suisse-arrest) heeft de belastingkamer van de Hoge Raad zich niet alleen uitgelaten over de fiscale duiding van het pleitbaar standpunt, maar tevens geoordeeld omtrent de strafrechtelijke duiding. Het is duidelijk dat de Hoge Raad met dit arrest éen lijn wilde trekken omtrent dit onderwerp in zowel het strafrecht als het belastingrecht. Daarvoor was ook aanleiding aangezien het tamelijk arbitrair is of een fiscale fraudeur een bestuurlijke boete krijgt van de inspecteur dan wel wordt geconfronteerd met een FIOD-onderzoek en een dagvaarding om te verschijnen voor de strafrechter. De wens tot convergentie, zoals nadrukkelijk kenbaar gemaakt door de President van de Hoge Raad, ${ }^{3}$ vloeide tevens voort uit de constatering dat de strafkamer 'preciezer' was ten opzichte van de meer rekkelijke invulling van het pleitbaar standpunt door de belastingkamer. Het product van de convergentie kan worden gelezen in het

2. HR 21 april 2017, ECLI:NL:HR:2017:638, BNB 2017/162

3. M.W.C. Feteris, 'Invloed van het strafrecht op het fiscale boeterecht', WFR 2015/140. 
arrest van 21 april 2017. Voor zover het de bestuurlijke boete betreft, overwoog de Hoge Raad als volgt:

3.4.5. Indien een onjuiste belastingaangifte wordt gedaan, kan ter zake daarvan geen vergrijpboete als bedoeld in de artikelen $67 \mathrm{~d}$ en $67 \mathrm{e}$ AWR worden opgelegd indien aan die aangifte een standpunt ten grondslag ligt dat gebaseerd kan worden op een pleitbare uitleg van het (fiscale) recht, in die zin dat de belastingplichtige ten tijde van het doen van die aangifte - naar objectieve maatstaven gemeten - redelijkerwijs kon en mocht menen dat deze uitleg en daarmee de door hem gedane aangifte juist was. In een dergelijk geval kan niet worden gezegd dat het aan opzet of grove schuld van de belastingplichtige te wijten is dat die aangifte onjuist is dan wel dat daardoor te weinig belasting is geheven, ook al wordt het aan die aangifte ten grondslag liggende standpunt later door de rechter onjuist bevonden. (...)'

In aanvulling op dit arrest overwoog de Hoge Raad op 20 december 2019 nog als volgt:

'2.3.2. Van een pleitbaar standpunt (een pleitbare uitleg van het (belasting)recht) is sprake indien de belastingplichtige ten tijde van het doen van aangifte naar objectieve maatstaven redelijkerwijs kon en mocht menen dat zijn uitleg van het belastingrecht juist was. Deze beoordeling naar objectieve maatstaven brengt mee dat degene die zich op een pleitbaar standpunt beroept, daarvoor een beroep kan doen op bronnen of opinies waarmee hij ten tijde van de aangifte niet bekend was. Indien kan worden vastgesteld dat de belasting- of inhoudingsplichtige van zo'n pleitbaar standpunt is uitgegaan, kan niet de vergrijpboete worden opgelegd die is voorzien wegens het opzettelijk niet, dan wel onjuist of onvolledig voldoen aan de aangifteplicht (artikel 67d AWR), en evenmin de vergrijpboete die staat op het opzettelijk of grovelijk onachtzaam niet, niet volledig dan wel niet binnen de gestelde termijn betalen van belasting die op aangifte behoort te worden voldaan of afgedragen (artikel 67f AWR).'

Voor deze bijdrage is relevant dat de belastingkamer deze rechtsregel ook formuleert voor situaties waarin de boete niet is opgelegd vanwege opzet, maar vanwege grove schuld. Uit de jurisprudentie kan worden opgemaakt dat daarvan sprake is in gevallen waarin de belastingplichtige met een ernstige mate van onachtzaamheid, onnadenkendheid of slordigheid heeft gehandeld. In dergelijke gevallen is in het Besluit Bestuurlijke Boeten Belastingdienst geformuleerd dat als uitgangspunt geldt dat een boete wordt opgelegd ter hoogte van 25\% van het bedrag dat te weinig aan belasting werd betaald. Het betreft dientengevolge een serieuze vergrijpboete, waarbij grove schuld als bestanddeel in de boetebepaling is opgenomen.
Dat op 21 april 2017 sprake was van een convergentiearrest blijkt uit de hierna geciteerde rechtsoverweging waarin de belastingkamer oordeelt over een beroep op een pleitbaar standpunt bij een 'strafvervolging'. Er kan geen twijfel over bestaan dat de volgende passage door de strafkamer werd geconcipieerd of in ieder geval werd geaccordeerd:

'3.4.7. Met betrekking tot een mogelijke strafvervolging geldt het volgende. Indien een onjuiste of onvolledige belastingaangifte wordt gedaan, maar de betrokkene ten tijde van het doen van die aangifte - naar objectieve maatstaven gemeten - redelijkerwijs kon en mocht menen dat deze aangifte juist en volledig was, bijvoorbeeld omdat deze gebaseerd was op een pleitbaar standpunt als hiervoor in 3.4 .5 bedoeld, kan niet worden gezegd dat hij opzettelijk een onjuiste of onvolledige aangifte heeft gedaan die ertoe strekt dat te weinig belasting wordt geheven, een en ander in de zin van artikel 69, lid 2, AWR. Daartoe is immers vereist dat de betrokkene opzettelijk heeft gehandeld, dus minst genomen met voorwaardelijk opzet, hetgeen betekent dat hij bewust de aanmerkelijke kans heeft aanvaard dat hij ten onrechte geen onderscheidenlijk een onjuiste of onvolledige aangifte heeft gedaan. Dat laatste doet zich niet voor indien, al dan niet achteraf bezien, de door de betrokkene aanvaarde kans dat de aangifte onjuist of onvolledig zou blijken te zijn, niet aanmerkelijk was. ${ }^{5}$

Dit arrest - en de vraag of al dan niet daadwerkelijk sprake was van convergentie tussen het strafrecht en het fiscale recht - heeft al heel wat pennen in beweging gebracht. Met name de volgende twee punten vallen op:

i. Uit de redactie van de strafrechtelijke overweging volgt dat het pleitbaar standpunt 'slechts' één van de redenen kan zijn waarom de belastingplichtige 'redelijkerwijs kon en mocht menen dat de aangifte juist en volledig was'. Dit volgt uit het expliciete gebruik van het woord 'bijvoorbeeld', waardoor op zijn minst genomen de indruk ontstaat dat het pleitbare standpunt één uitwerking is van het 'redelijkerwijs kon en mocht menen', maar dat andere omstandigheden de conclusie dat men redelijkerwijs kon en mocht menen dat de aangifte juist en volledig was, tevens kunnen rechtvaardigen. De uitleg die de strafrechter heeft gegeven is dus ruimer dan die van de fiscale rechter.

ii. Uit de overweging van de Hoge Raad volgt dat het redelijkerwijs kunnen en mogen menen dat de aangifte juist is, aan opzet in de weg staat. De Hoge Raad heeft in het - nadien door de strafkamer herhaalde - tweede deel van de overweging het pleitbaar standpunt in het leerstuk van het voorwaardelijk opzet geplaatst.

Uit de bewoordingen van de Hoge Raad valt aldus op te maken dat een pleitbaar standpunt bij delicten waarin 
opzet als bestanddeel is opgenomen, geen exceptie maar een zuiver opzetverweer is. ${ }^{6}$

\section{Convergentie bij schuld als bestanddeel?}

$\mathrm{Nu}$ de Hoge Raad het pleitbare standpunt in de strafrechtelijke doctrine heeft geplaatst in de sleutel van de aanmerkelijke kans bij voorwaardelijke opzet, rijst de vraag op welke wijze een beroep op een pleitbaar standpunt in het strafrecht een plaats kan krijgen indien de ten laste gelegde strafrechtelijke bepaling opzet niet als bestanddeel kent. De niet doleuze delicten in het fiscale strafrecht kunnen worden gevonden in artikel 68 AWR en deze bevatten schuld niet als bestanddeel. Mogelijk kan een beroep op een fiscaal pleitbaar standpunt eveneens worden gedaan als de tenlastelegging (niet-doleuze) commune delicten betreft maar de onderliggende casus wel over de schending van fiscale normen gaat. Naar aanleiding van de erkenning van het pleitbaar standpunt als fenomeen binnen de strafrechtelijke doctrine door het Credit Suisse-arrest, diende zich al de vraag aan of het pleitbaar standpunt ook toepassing kan vinden ten aanzien van andere, dat wil zeggen niet-fiscale, delicten. Reijntjes gaat in zijn annotatie bij NJ 2018/271 in op het arrest van 3 oktober $2017,{ }^{7}$ waarin de vraag aan de orde kwam of sprake was van een pleitbaar standpunt ten aanzien van een onjuist bezwaarschrift, dat als een schending van artikel 225 Wetboek van Strafrecht ten laste was gelegd. De Hoge Raad casseerde op de grond dat een bezwaarschrift geen bewijsbestemming had, en stelde vast dat het cassatiemiddel met betrekking tot het pleitbare standpunt geen behandeling behoefde. Desalniettemin citeerde de Hoge Raad alle overwegingen uit voormeld Credit Suisse-arrest van de belastingkamer van de Hoge Raad. Reijntjes ziet hierin een bevestiging dat een fiscaal pleitbaar standpunt ook een rol kan spelen indien commune delicten in de tenlastelegging zijn opgenomen:

'Waarschijnlijk is de boodschap, die de strafkamer heeft willen afgeven niet alleen dat zij de belastingkamer volgt, maar ook dat hiervoor niet de tenlastelegging doorslaggevend is, maar de onderliggende casus. Het zou ook wel heel vreemd zijn wanneer het OM, alleen door een andere strafbepaling te hanteren, beroep op een pleitbaar standpunt de pas zou kunnen afsnijden. Dat kan nooit de bedoeling zijn.'

Ook A-G Bleichrodt oordeelt in zijn conclusie van 19 mei $2020^{8}$ dat een beroep op een pleitbaar standpunt relevant is voor de vraag of een aangifte omzetbelasting die (tevens) als vals geschrift ten laste werd gelegd, tot

6. Zo ook I. Leenders en A. Klaasse, 'Opzet in de AWR: het pleit beslecht?', WFR 2018/111.

7. HR 3 oktober 2017, ECLI:NL:HR:2017:2542, NJ 2018/270 m.nt. Reijntjes.

8. A-G Bleichrodt 19 mei 2020, ECLI:NL:PHR:2020:493. een veroordeling kan leiden. Als wordt aangenomen dat een pleitbaar standpunt relevant kan zijn bij een tenlastelegging waarop slechts commune delicten prijken, is het interessant om te bezien of dit ook geldt voor (bepaalde) delicten waarvan schuld een bestanddeel vormt.

In veel fiscale strafzaken wordt ook witwassen ten laste gelegd. De gedachte aan artikel 420quater Sr (schuldwitwassen) ligt deswege voor de hand. Als de verdachte zich verdedigt tegen de beschuldiging dat hij een voorwerp verwierf, voorhanden had of overdroeg terwijl hij redelijkerwijs moest vermoeden dat het voorwerp - onmiddellijk of middellijk - afkomstig is uit enig misdrijf, kan hij zich dan succesvol beroepen op een pleitbaar standpunt? Een opzetverweer, specifiek op de afwezigheid van een aanmerkelijke kans, kan het niet zijn, want dat bestanddeel komt als zodanig niet voor op de tenlastelegging. Betoogd kan worden dat dit bestanddeel wel op een niveau lager aanwezig is, te weten in het opzet ten aanzien van het fiscale gronddelict waaruit gelden zouden zijn witgewassen. Een eventueel pleitbaar standpunt komt via het schuldwitwassen dan als het ware 'indirect' in beeld. Immers: geen misdrijf, geen witwassen. Omdat het grondmisdrijf waaruit wordt witgewassen niet hoeft te worden benoemd door de rechter, en een verdachte bovendien niet zelf betrokken hoeft te zijn geweest bij het gronddelict, is het in een dergelijke situatie zuiverder om het verweer van een pleitbaar standpunt te betrekken op het schuldbestanddeel voor schuldwitwassen.

Uit Tekst \& Commentaar strafrecht, 12e druk, 2018, aant. 8 bij artikel 420 quater $\mathrm{Sr}$ kan worden opgemaakt dat de bepaling schuld vereist ten aanzien van de omstandigheid dat het voorwerp van misdrijf afkomstig is: de pleger moet dit redelijkerwijs vermoeden. Uit HR 17 december 1985, NJ 1986/428 kan worden opgemaakt dat dit duidt op 'grove of aanmerkelijke onvoorzichtigheid'. De Hullu9 stelt dat de kern gelegen lijkt te zijn in 'verwijtbare aanmerkelijke onvoorzichtigheid'. Uit de parlementaire geschiedenis ${ }^{10}$ kan nog het volgende worden afgeleid:

'Het bestanddeel dat de betrokken persoon «weet» (artikel 420bis) of «redelijkerwijs moet vermoeden» (artikel 420quater) dat het (voorwerp) - onmiddellijk of middellijk - afkomstig is uit enig misdrijf is in paragraaf 3 al aan de orde geweest. «Weten» is uitdrukking van opzet. Hieronder valt ook voorwaardelijk opzet: willens en wetens de aanmerkelijke kans aanvaarden dat men een voorwerp verbergt (of een voorwerp verwerft enz.) dat uit misdrijf afkomstig is. «Redelijkerwijs moet vermoeden» duidt op de zogenaamde schuld of culpa. Dit betekent aanmerkelijke onvoorzichtigheid: bij enig nadenken had

9. J. de Hullu, Materieel strafrecht. Over algemene leerstukken van strafrechtelijke aansprakelijkheid naar Nederlands recht, Deventer: Kluwer 2018, p. 266.

10. MvT Kamerstukken I/ 1999/2000, 27 159, nr. 3, p. 15 
de verdachte kunnen vermoeden dat het om een voorwerp afkomstig uit misdrijf ging; verdachte had niet zonder nader onderzoek met het voorwerp mogen handelen. De twee varianten - opzet en culpa - treffen we ook aan bij de helingbepalingen (zie artikelen 416 en 417 bis $\mathrm{Sr}$ ).'

Het in ernstige mate tekortschieten in een onderzoeksplicht die in de omstandigheden van het geval had mogen worden verwacht, kan voldoende zijn om schuld vast te stellen, aldus de Hoge Raad in zijn arrest van 17 december 2002, NJ 2003/177.

De Hullu ${ }^{11}$ onderkent een normatieve en een psychische component bij het begrip culpa. Bij de normatieve component zijn aspecten als geoorloofd risico, wederrechtelijkheid en Garantenstellung aan de orde: 'Het gevolg is aan het onvoorzichtige gedrag te wijten omdat het gedrag in strijd was met geschreven en ongeschreven normen en omdat van deze verdachte anders mocht worden verwacht.' Mijns inziens heeft de strafrechter voldoende aanknopingspunten binnen de huidige doctrine omtrent schuld om te oordelen dat schuld als bestanddeel niet kan worden bewezen ingeval sprake is van een pleitbaar standpunt. Van een verdachte met een pleitbaar standpunt zal immers niet lichtvaardig kunnen worden aangenomen dat hij ongeoorloofde risico's heeft genomen of heeft gehandeld in strijd met hetgeen van hem op basis van geschreven en ongeschreven recht had mogen worden verwacht. Indien geen schuld wordt aangenomen bij een pleitbaar standpunt, wordt daarmee tevens invulling gegeven aan het streven om ten aanzien van het beroep op een pleitbaar standpunt convergentie te bereiken tussen de jurisprudentie van de strafkamer en de belastingkamer.

\section{Geen opzet of schuld als bestanddeel}

In het belastingrecht kunnen op grond van hoofdstuk VIIIA, afdeling 1 , paragraaf 1 van de AWR verzuimboeten worden opgelegd tot een maximumbedrag van $€$ 5.514. De boetebepalingen kunnen worden gevonden in de artikelen 67a, 67b en 67c AWR. Voor het opleggen van deze boeten is geen opzet of (grove) schuld vereist. De inspecteur zal een dergelijk verwijt dan ook niet aannemelijk behoeven te maken. In de fiscale doctrine is aan de orde gekomen in hoeverre bij de schending van dergelijke bepalingen een beroep op een pleitbaar standpunt effect zou kunnen sorteren. De rechtsontwikkeling is op dit punt echter enigszins blijven steken als gevolg van beleidsmatige uitingen door de Staatssecretaris van Financiën. Zo nam hij op 9 november 2000 (nr. RTB2000/2474M) een besluit met de volgende inhoud:
'Als de inspecteur aannemelijk acht dat het standpunt van de belanghebbende pleitbaar is, laat hij oplegging van een verzuimboete achterwege. Is inmiddels een verzuimboete opgelegd, dan vernietigt hij de boetebeschikking. Is er sprake van een pleitbaar standpunt, dan kan de belanghebbende geen verwijt worden gemaakt dat er aanvankelijk geen of te weinig belasting is geheven.

Onder een pleitbaar standpunt wordt verstaan een opvatting over de kwalificatie van de feiten of de toepassing van het recht op de feiten die in redelijkheid verdedigbaar is.'

Nadat dit besluit was ingetrokken, werd een soortgelijke tekst opgenomen in het Besluit Bestuurlijke Boeten Belastingdienst. In paragraaf 4, lid 2 kan het volgende worden gelezen:

'Van een pleitbaar standpunt is sprake als een door belanghebbende ingenomen standpunt, gelet op de stand van de jurisprudentie en de heersende leer, in die mate juridisch pleitbaar of verdedigbaar is dat belanghebbende redelijkermijs kan menen juist te handelen. Is er sprake van een pleitbaar standpunt, dan kan de belanghebbende er geen vermijt van morden gemaakt dat er aanvankelijk geen of te meinig belasting is geheven. Een pleitbaar standpunt sluit het opleggen van zomel een verzuimboete als een vergrijpboete uit.'

In zijn recente arrest van 20 december 2019, BNB 2020/43 heeft de belastingkamer van de Hoge Raad de principiële vraag hoe het pleitbaar standpunt moet worden geduid indien opzet of (grove) schuld) niet vereist is, enigszins ontweken. De betreffende rechtsoverweging luidt als volgt:

'2.3.3 De in artikel 67c AWR voorziene verzuimboete, die aan belanghebbende is opgelegd, kan op grond van de enkele constatering dat de belasting niet, onvolledig of te laat is betaald en derhalve zonder onderzoek naar de mate waarin de belasting- of inhoudingsplichtige daarvan een verwijt moet worden gemaakt, worden opgelegd. In paragraaf 4 van het Besluit Bestuurlijke Boeten Belastingdienst is bepaald, voor zover hier van belang, dat een pleitbaar standpunt ook het opleggen van een verzuimboete (zoals die van artikel 67c AWR) uitsluit.'

Fiscale jurisprudentie waarin het beleid niet wordt gebruikt om de discussie te vermijden, is schaars. In oudere uitspraken ${ }^{12}$ overweegt de Hoge Raad als volgt:

'De omstandigheid dat het door hem met betrekking tot de verschuldigdheid van die belasting ingenomen standpunt, volgens hetwelk het onderhavige motorrijtuig niet was ingericht voor het vervoer van 
personen, door het hof als juist is aanvaard, noopt tot de gevolgtrekking dat, ook al zou bedoeld standpunt na cassatie onjuist worden bevonden, niet kan worden gezegd dat bij belanghebbende enige schuld aanwezig is aan het feit dat te weinig belasting geheven is.'

In deze arresten wordt een pleitbaar standpunt derhalve 'doorvertaald' naar de schulduitsluitingsgrond afwezigheid van alle schuld. In zijn arrest van 2 maart 2012 liet de Hoge Raad de vernietiging van de boete in stand vanwege een pleitbaar standpunt. ${ }^{13}$ Het betrof een boete die door de inspecteur kon worden opgelegd zonder dat deze opzet of grove schuld aannemelijk moest maken.

In haar dissertatie (p. 141 e.v.) heeft $\operatorname{Kors}^{14}$ aandacht besteed aan de vraag of het pleitbaar standpunt kan worden ingepast binnen de algemene strafuitsluitingsgronden. Op haar conclusie dat het pleitbaar standpunt niet aansluit bij de bestaande rechtvaardigingsgronden, kan niets worden afgedongen. Van het ontbreken van materiële wederrechtelijkheid of het geven van uitvoering aan een wettelijk voorschrift is geen sprake. De schulduitsluitingsgrond afwezigheid van alle schuld lijkt op het eerste oog meer perspectief te bieden; zoals hiervoor beschreven is dat ook de variant van de strafuitsluitingsgronden die de Hoge Raad heeft gebruikt.

Een van de verschijningsvormen van afwezigheid van alle schuld is rechtsdwaling. Daarvan is sprake indien een belastingplichtige verontschuldigbaar dwaalt omtrent de wederrechtelijkheid van zijn handelingen. ${ }^{15} \mathrm{Uit}$ het arrest van de strafkamer van de Hoge Raad van 26 januari 1971, NJ 1971/322 kan echter worden afgeleid dat van rechtsdwaling nog geen sprake is 'op grond van het enkele feit dat men het standpunt (...) in redelijkheid kan bepleiten'. Een succesvolle integratie van het fiscaal-boeterechtelijke leerstuk van het pleitbare standpunt lijkt derhalve niet eenvoudig te kunnen plaatsvinden door middel van een beroep op rechtsdwaling. ${ }^{16}$ Het vorenstaande neemt echter niet weg dat zich situaties kunnen voordoen waarin de belastingplichtige - zonder enige twijfel - ervan overtuigd was een correcte aangifte te doen. Kors ${ }^{17}$ is voor dergelijke belastingplichtigen wel erg streng. Van verontschuldigbare dwaling kan in die situaties naar haar overtuiging pas sprake zijn als de verdachte een inspanning heeft verricht 'die, gegeven de omstandigheden, redelijkerwijs van hem kon worden gevergd om te voorkomen dat hij zou dwalen'. Het ligt echter niet voor de hand dat iemand die geen twijfel heeft omtrent de correctheid van het standpunt dat hij in zijn aangifte verwerkt, inspanningen verricht om dwalen te voorkomen. Maar als dat wel zou gebeuren, is de variatie aan mogelijke inspanningen ook beperkt. Allereerst had de belastingplichtige zich

13. HR 2 maart 2012, ECLI:NL:HR:2012:BP3858, BNB 2012/123.

14. M.M. Kors, Pleitbaar standpunt in het fiscale boete- en strafrecht (diss. Nijmegen), Deventer: Kluwer 2017, p. 141

15. HR 22 november 1949, ECLI:NL:HR:1949:1, NJ 1950/180.

16. Kors 2017, p. 149, en G.J.M.E. de Bont, 'Opzet in fiscaal boete- en strafrecht', TFB 2002/6, p. 5 e.v.

17. Kors 2017, p. 151. kunnen verdiepen in de onderliggende fiscale materie. Deze variant is voor de fiscale leek veelal onhaalbaar. De andere optie zou zijn dat de belastingplichtige zich wendt tot een persoon aan wie 'zodanig gezag valt toe te kennen dat hij in redelijkheid op de deugdelijkheid van het advies mocht vertrouwen', aldus Kors onder verwijzing naar jurisprudentie. ${ }^{18}$ Dergelijke inspanningen zouden echter pas verwacht mogen worden als de belastingplichtige kan worden verweten dat hij nader onderzoek had moeten (laten) doen naar de standpunten die hij in de aangifte heeft ingenomen.

Kors onderzoekt in haar dissertatie ${ }^{19}$ ook nog of de andere variant van afwezigheid van alle schuld, te weten de schulduitsluitingsgrond maximaal betrachte zorg, van toepassing kan zijn bij een beroep op een pleitbaar standpunt. De vraag is dan of de belastingplichtige aan de vereiste zorg- en inspanningsverplichtingen heeft voldaan om te voorkomen dat een onjuiste aangifte werd gedaan. Met Kors kan worden geconcludeerd dat deze strafuitsluitingsgrond een eigen beoordelingskader kent, dat niet aansluit op een beroep op een pleitbaar standpunt. Het is voor deze schulduitsluitingsgrond niet relevant of er een pleitbaar standpunt is ingenomen, maar 'of de belastingplichtige alle in redelijkheid te verlangen maatregelen heeft getroffen om te voorkomen dat zijn aangifte onjuist is'. Deze vorm van afwezigheid van alle schuld kan dus evenmin van toepassing zijn.

Uit de hiervoor aangehaalde arresten van de Hoge Raad uit 1992 leidt Kors voorzichtig af dat de Hoge Raad (ook bij verzuimboeten) uitgaat van een objectieve werking van het pleitbaar standpunt. $\mathrm{Bij}$ de objectieve variant is niet relevant wat de verdachte heeft geweten en gewild op het moment dat hij de aangifte deed die nadien als onjuist is aangemerkt. Doorslaggevend is of het ingenomen standpunt nadien pleitbaar is. Deze conclusie lijkt met het Credit Suisse-arrest nader te worden ondersteund. Daarin werd immers het objectieve karakter van dit verweer zowel in het belastingrecht als het strafrecht geaccepteerd. Het valt moeilijk voor te stellen dat het ten aanzien van delicten waarbij opzet (of grove schuld) als bestanddeel bewezen dient te worden, niet relevant is wat de belastingplichtige heeft gedacht ten tijde van het doen van aangifte, maar dat dit opeens anders zou zijn indien er te weinig belasting wordt betaald en de wet niet voorschrijft dat opzet of grove schuld dient te worden bewezen.

Kors stelt zich in haar dissertatie ${ }^{20}$ op het standpunt dat er bij een objectief pleitbaar standpunt slechts een strafuitsluitingsgrond van toepassing zou dienen te zijn 'als de belastingplichtige er ten tijde van het doen van de aangifte van uit is gegaan dat hij een juiste aangifte deed of in ieder geval heeft verondersteld dat hij een pleitbaar standpunt innam'. Als de argumentatie achter de juris-

\footnotetext{
18. HR 13 december 1960, NJ 1961/416; HR 4 april 2006, NJ 2007/144 HR 26 februari 2008/148.

19. Kors 2017, p. 151.

20. Kors 2017, p. 286.
} 
prudentie van het pleitbare standpunt wordt bezien, bestaat er echter geen aanleiding om de subjectieve gedachten van de belastingplichtige een prominentere rol te geven bij verzuimboeten. Uit het Credit Suissearrest vloeit voort dat er ruimte dient te zijn voor een 'pleitbaar standpunt'-verweer als gevolg van het feit dat de fiscale wetgeving uitermate complex (en veranderlijk) is. Daarenboven is de belastingplichtige jaarlijks verplicht aangifte te doen. Het is niet een vrijwillige handeling die hij verricht. Hij is verplicht zich jaarlijks op het spreekwoordelijke fiscale mijnenveld te begeven. Kors $^{21}$ merkt daarenboven nog als grondslag voor de 'pleitbaar standpunt'-jurisprudentie aan: 'de vrijheid van een belastingplichtige om de eigen interpretatie en toepassing van het recht aan de belastingrechter voor te leggen en de vrijheid van een belastingplichtige om zijn eigen - voor hem gunstigste - interpretatie en toepassing te volgen'. Met een dergelijke achtergrond van het leerstuk van het pleitbare standpunt is er geen aanleiding, laat staan noodzaak, om een onderscheid te maken tussen delicten waarin opzet of schuld als bestanddeel is opgenomen en de delicten waarbij dat niet het geval is. Het argument dat wordt aangevoerd, te weten dat een strafuitsluitingsgrond ook toepasbaar zou zijn bij opzetdelicten, gaat nagenoeg nimmer op. Als opzet of grove schuld aannemelijk zijn geacht door de rechter, zal deze niet eenvoudig kunnen vaststellen dat er toch een schulduitsluitingsgrond bestaat. Ook De Hullu ${ }^{22}$ merkt op dat 'na het bewezen verklaren van culpa het vaststellen van afwezigheid van alle juridische relevante schuld (...) niet meer goed denkbaar is'.

Het valt te betreuren dat de Hoge Raad in zijn arrest van 20 december 2019, $B N B$ 2020/43 geen nadere invulling heeft gegeven aan de belangrijkste taak en verantwoordelijkheid van de Hoge Raad: rechtsontwikkeling. Niets - en zeker niet het beleid van de Staatssecretaris - had de Hoge Raad ervan behoeven te weerhouden op dit punt nadere rechtsregels te formuleren. Bij gebreke aan recente jurisprudentie lijkt de overweging in het arrest van 2 maart 2012 leidend waarbij de Hoge Raad oordeelde dat het hof (ten onrechte) de naheffing had vernietigd, maar aangezien 'het Hof (belanghebbende) op rechtskundige gronden in het gelijk heeft gesteld, moet het ervoor worden gehouden dat belanghebbende een pleitbaar standpunt heeft ingenomen' waardoor de vernietiging van de verzuimboete in stand bleef. Het pleitbare standpunt wordt door de Hoge Raad niet geherkwalificeerd tot afwezigheid van alle schuld, maar geaccepteerd als een bijzondere strafuitsluitingsgrond. Uit dit arrest kan worden opgemaakt dat het 'pleitbaar standpunt'-verweer bij delicten waar opzet of (grove) schuld geen bestanddeel vormen als een bijzondere in de rechtspraak ontwikkelde exceptie dient te worden aangemerkt. In het kader van het streven naar convergentie zou een arrest van de Hoge Raad welkom zijn waarin deze lijn voor zowel het strafrecht als het belastingrecht wordt bevestigd.

\section{Conclusie}

Met het wijzen van het Credit Suisse-arrest heeft de Hoge Raad het leeuwendeel van de nagestreefde convergentie tussen de strafkamer en de belastingkamer bereikt ten aanzien van het leerstuk van een pleitbaar standpunt. Het pleitbaar standpunt kent in beide rechtsgebieden een objectieve werking waardoor de intentie en kennis van de verdachte belastingplichtige ten tijde van het doen van aangifte niet van belang zijn. Voorts is helder dat het beroep op een pleitbaar standpunt bij doleuze delicten geplaatst dient te worden in de sleutel van een opzetverweer. Deze laatste keuze is toe te juichen, maar daarmee rijst de vraag op welke wijze dit verweer kan worden toegepast bij culpoze delicten. Als schuld als bestanddeel is geformuleerd, bestaat er voldoende grondslag om het pleitbaar standpunt mee te nemen in de algemenere vraag of sprake is van schuld. Als schuld echter niet als bestanddeel is opgenomen, lijkt de enige oplossing dat een pleitbaar standpunt als een bijzondere strafuitsluitingsgrond wordt geaccepteerd. De belastingkamer heeft daarvoor al eens een voorzet gegeven. De resterende vraag is of de strafkamer deze - in het licht van de convergentie - wenst te accepteren. 